\title{
CARTESIANOS O HERMENEÚTICOS: EL MEMORIAL ACADÉMICO COMO FORMA DE AUTOBIOGRAFÍA DOCENTE EN BRASIL*
}

\author{
Cartesian or hermenutics: academic memoir as a form of teacher autobiography \\ in brazil
}

Wilton C. L. Silva

José González-Monteagudo

Fecha recepción: 23/08/2016

Fecha aceptación: 01/11/2016

RESUMEN: La recuperación del pasado y el trabajo en torno a las experiencias vividas, individuales y colectivas, constituyen temas actuales y proliferan saberes, instituciones y métodos para rescatar, organizar y documentar la memoria. En la tradición académica brasileña existe un documento de naturaleza autobiográfica, el memorial académico, en el que el docente universitario presenta, para la progresión de su carrera, una narrativa de su recorrido personal, intelectual y profesional. Como forma de escritura el memorial académico es condicionado por una tradición institucional, presentando diferentes niveles de subjetivación a lo largo del tiempo y caracterizándose como uno de los raros momentos en que se presenta como legítima la palabra del académico sobre sí mismo. Pretendemos apuntar las particularidades de esa manifestación de escritura sobre sí mismo, el memorial académico, buscando discutir las opciones de los docentes por modelos narrativos que enfatizan la formalidad, cartesianos, o que adoptan mayor subjetividad, hermenéuticos.

PALABRAS CLAVES: Autobiografía, memorias de profesores, modelos narrativos, memorial académico, Brasil.

ABSTRACT: The recovery of the past and work around individual and collective lived experiences are current issues while progressively spread knowledge, institutions and methods for collecting, organizing and documenting memory. In the Brazilian academic tradition there is an autobiographical document, the academic memoir, in which the university lecturer presents the progression of his or her career, under the format of a narrative focused on personal, intellectual and professional dimensions. As a form of academic, formal writing, the academic memoir is framed by institutional traditions, presenting different levels of subjectivity over time and it ischaracterized as one of the rare moments in which the word of academics is presented as a legitimated exercise in itself. This paper discusses the main traits of these narrative documents, stressing the influence of the narrative turn and documenting its contents and discursive styles. We propose to distinguish two narrative models of the academic memoirs: one more objective and distant, the another more subjective and hermeneutic.

KEY WORDS: Autobiography, Lecturer's Memoirs, Narrative Models, Academic Memoir, Brazil.

* Este texto es resultado de una estancia de investigación, realizada en la Universidad de Sevilla (España) entre enero y febrero de 2016, con una beca del Programa de Movilidad de Profesores e Investigadores Brasil-España de la Fundación Carolina. 


\section{Introducción: La autobiografia en contexto universitaro}

"¿De qué puede hablar com el máximo placer um hombre honrado?: de sí mismo." (Fiódor Dostoiévski, Notas sobre el subterrâneo)

La escritura de sí, "écriture de soi", es un término acuñado por Michel Foucault (1990), que se relaciona con sus investigaciones sobre la "cultura del yo". La escritura de sí comprende una forma de manifestación discursiva en la cual el sujeto se posiciona en relación a sí mismo desde un discurso construido en primera persona, con un punto de vista totalizador y retrospectivo (Foucault, 1990).

Las narrativas de vida ganan relevancia a lo largo de la cultura occidental a partir de la secularización de la sociedad burguesa, con el refuerzo del individualismo y la sustitución de una causalidad externa de la providencia o del destino por la causalidad psicológica. Esto implica una historicidad consciente de la propia existencia, así como la sustitución de la problemática de la manifestación de un carácter ya existente por la de la formación de un carácter (Delory-Momberger, 2001 y 2004).

Así, las narrativas en las que narrador y personaje son la misma persona caracterizan la expresión literaria de la autobiografía, situación en la cual la identidad entre autor y narrador rompe con las instancias dicotómicas que suelen caracterizar los géneros de ficción. Lejeune (2008, p. 48) creó una definición bastante citada sobre lo que constituye el texto autobiográfico: "una narrativa en prosa en la que una persona real hace una retrospectiva de su personalidad. Tal definición establece criterios de identidad del autor/narrador (una persona real), de la forma del lenguaje (narrativa en prosa), de la temática (la vida individual y la historia de su personalidad) y de la perspectiva (retrospectiva)".

Este tipo de texto inspira un amplio abanico de estudios, en diversas áreas de las ciencias humanas, que abarca la construcción y análisis de relatos personales en un género de investigación que enfatiza términos como "narrativas de vida", "auto/biografía", "escrituras del yo", "escrituras de sí" e "historia de vida", entre otros. Esta amplitud de estudios surge como reflejo de cambios conceptuales en las ciencias humanas en general a partir de las décadas finales del siglo XX, cuando, según diversos autores, ocurrió un "retorno del sujeto" que se manifestó como consecuencia de un "giro subjetivo" (Sarlo, 2007) capaz de justificar la creación de un "espacio biográfico" (Arfuch, 2002), momento en el cual una infinidad de pequeños relatos y de múltiples identidades ocuparon los lugares de legitimidad y enunciación anteriormente monopolizados por los grandes relatos y por identidades hegemónicas.

En una nueva dinámica de exposición de los contenidos vivenciales y con una amplitud de carácter global, actualmente posible gracias a las nuevas tecnologías de la información, más allá de las fronteras físicas, tradiciones linguiísticas y ámbitos culturales, surgen múltiples opciones estéticas y estilísticas que abarcan distintas formas y diversos soportes, como la autoficción, el docudrama, los reality shows y las redes sociales, entre otros (Arfuch, 2013). Así, el mercado editorial y el campo académico ofrecen entrevistas, testimonios, memorias, manuscritos, cuadernos de notas, de viaje, de infancia, correspondencias, postales y papeles sueltos como piezas de un puzzle que presenta partes de la interioridad, del pensamiento y de la vivencia de sus autores.

Es dentro de este contexto que el campo de la educación incorporó los estudios cualitativos teniendo las historias de vida como metodología tanto para el estudio de la experiencia de estudiantes y de educadores, en la búsqueda de un enfoque capaz de crear un espacio de autorreflexión de los sujetos y afirmar la riqueza de los procesos de subjetivación envueltos en las relaciones de enseñanza-aprendizaje. En la historia de la educación, la relación entre biografía y aprendizaje surge en Francia en 1970, con los trabajos de Henri Desroche, en la École des Hautes Études en Sciences Sociales, al proponer la autobiografía razonada, que tenía por objetivo utilizar la historia de vida como proceso de "investigación- 
acción-formación". Esta perspectiva tendrá continuidad con diferentes investigadores pioneros, como Gaston Pineau, en Canadá, Bernadette Courtois y Guy Bonvalot, en Francia, Marie-Chistine Josso y Pierre Dominicé, en Suiza, Guy de Villers, en Bélgica, António Novoa, en Portugal, y Antonio Bolívar en España (Passeggi, Souza y Vicentini, 2011, p. 375).

En Brasil, el área de Historia de la Educación, en la década de los 90, asistió a un "giro biográfico" y el campo de investigación de la profesión docente incorporó discusiones sobre la forma en que los profesores vivencian los procesos de formación y ejercen la reflexión sobre las experiencias en el magisterio, en trabajos basados en las historias de vida como método de investigación cualitativa y como práctica de formación (Passeggi, Souza y Vicentini, 2011, p. 370). No obstante, en el caso brasileño, este tipo de escritura autorreflexiva se desarrolla más entre educadores de los niveles básicos y medios de enseñanza, mostrándose prácticamente inexistente entre los profesores de nivel superior.

Por otro lado, hay en la carrera docente universitaria del país la exigencia burocrática de un documento para el ascenso profesional a lo largo de la carrera docente que se caracteriza por su dimensión autobiográfica, el memorial académico. Tal documento tiene como finalidad satisfacer exigencias institucionales para la progresión en la carrera docente, describiendo la trayectoria del docente, con énfasis en sus actividades de investigación, publicaciones en revistas indexadas, actividades en curso de posgrado, conferencias, la producción material didáctico cualificado, cursos de extensión y demás actividades pertinentes a su área de actuación. Este tipo de documento puede ser abordado como fuente de investigación autobiográfica, en relación con las retóricas discursivas y escriturales propias del ethos de cada área disciplinar (Silva, 2015a y 2015b). Por su parte, Schweiger (2009) compara los rasgos de género textual y las funciones entre el "Memorial Académico" brasileño y el "Akademischer Lebenslauf", usual en Alemania.

El memorial académico no solo es utilizado como criterio de evaluación del mérito académico del candidato, sino que también se presenta como uno de los raros momentos en los cuales se legitima el discurso del intelectual sobre sí mismo, abordando desde la elección de la profesión y la formación inicial hasta el desarrollo de la carrera docente, así como las perspectivas personales, transiciones, prácticas, vivencias y recuerdos, en tanto que "experiencia". Desde el año 2000, en sintonía con paradigmas similares producidos en diferentes ámbitos geográficos y lingüísticos (Biographical Research en el ámbito anglosajón, Biographieforschung en Alemania y Recherche biographique en éducation en el área francófona), se produce una progresiva institucionalización de la investigación (auto)biográfica en el campo de la historia de la educación, ampliando la reflexión más allá del lenguaje escrito o hablado, con fotobiografías, audiobiografías, videobiografías y modalidades hipertextuales, como blogs, redes, webs para almacenar registros de vida o, incluso, la opción de vivir una vida virtual (Passeggi, Souza y Vicentini, 2011, p. 380).

La importancia de la escritura biográfica en educación se relaciona con procesos de formación discente y docente que consideran que, en una sociedad caracterizada por la complejidad y fuerza de las identidades, el enfoque autorreflexivo permitiría el desarrollo de sensibilidades, habilidades y competencias para una mejor comprensión de sí y del otro (González-Monteagudo, 2008).

La comprensión de quiénes somos pasa por la percepción de cómo nos convertimos en lo que somos y cuales serían nuestras posibilidades de llegar a ser, siempre en una perspectiva de alteridad, en relación con los otros, siguiendo dimensiones relativas al pasado recordado, el presente vivido y el futuro proyectado. Como afirman Gauer y Gomes (2008, p. 508), tales "memorias reflejan patrones de expectativas culturales, permitiendo al individuo verificar la mayor o menor adecuación de su propia trayectoria individual a las convenciones sociales que son los eventos que normalmente hacen parte de una historia de vida." 
Lo que nos interesa específicamente aquí es presentar de forma panorámica una determinada tradición intelectual de escritura autobiográfica en la universidad brasileña y caracterizar dos modelos distintos en su proceso de estructuración, que intentamos anticipar en el título de nuestro artículo. Para desarrollar nuestros argumentos, nos apoyamos en un corpus textual de 39 memoriales producidos en Brasil, que fueron objeto de una publicación anterior de uno de los coautores (Silva, 2015a), en la cual se ofrecen detalles más precisos sobre el enfoque metodológico, que retomamos aquí de manera resumida.

En primer lugar, hay que señalar que la denominación de cartesianos versus hermenéuticos pretende retomar respectivamente enfoques descriptivos frente a narrativos. Estas dos miradas nos parece que resumen bien una de las grandes líneas transversales que caracteriza el género de los memoriales. Se han analizado un total de 39 memoriales, escritos por profesores universitarios de Historia y de Antropología de las universidades de São Paulo y Estatal de Campinas, que constituyen las dos universidades públicas más importantes de Brasil. Resaltamos la necesidad de tener en cuenta que estos memoriales han sido producidos por historiadores y antropólogos. Al tratarse de campos disciplinares de las ciencias sociales, es evidente que la escritura autobiográfica memorialista está influida por los paradigmas y modos peculiares de investigadores y docentes que trabajan sobre identidades, subjetividades y cambios socioculturales. Esto es particularmente relevante para el caso de los antropólogos, que están habituados a escribir diarios de campo, notas observacionales y otros registros narrativos de carácter abierto y cualitativo. Los memoriales comentados aquí cubren un período temporal comprendido entre 2000 y 2014. Teniendo en cuenta que los memoriales comenzaron en la década de los 30 del siglo XX, los memoriales del siglo XXI se caracterizan, como sería lógico esperar, por un claro predominio del enfoque narrativo o hermenéutico. Hay que aclarar que hasta la fecha no se han realizado estudios sobre los memoriales con una perspectiva de género. Se trata de una laguna en este campo, que esperamos poder trabajar en el futuro.

\section{El memorial como escritura autobiográfica en educación}

"Del individuo tenemos que partir, aunque sea para abandonarlo" (Fernando Pessoa, Aforismos e afins)

En la tradición institucional de la universidad brasileña la exigencia de memoriales se inició en las universidades federales a partir de 1934, donde se extendió hasta 1968, como exigencia en los concursos de profesor catedrático, y posteriormente de profesor titular. Esta práctica se mantiene actualmente como una estrategia para la consolidación de la carrera docente, tal y como sucede, por ejemplo, en las universidades del estado de São Paulo, en donde aún existe la figura profesional de la "libre docencia", como paso previo a la titularidad de un puesto permanente.

En realidad, el origen del memorial, entendido como un relato crítico de la trayectoria cultural e intelectual del individuo, así como de sus expectativas profesionales y académicas, es una exigencia que se remonta al Exposé des titres et travaux scientifiques, característico de la carrera académica francesa.

Varios autores han propuesto precisiones definiciones sobre los memoriales. Moraes (1985, p. 36) proponía diferenciar el memorial del curriculum vitae. Así, este autor definía el curriculum vitae como "el conjunto de informaciones sobre las habilitaciones del individuo, presentado de forma secuencial y sin comentarios", mientras que el memorial sería un "análisis de informaciones del individuo presentado de manera crítica" (Moraes, 1985, p. 36). Por su parte, D’Onofrio (1999, p. 74) identifica el memorial académico como "un currículo comentado, la historia de una vida reflexionada, el auto-análisis de los hechos memorables, 
con el objetivo de iluminar la evolución en el área de conocimiento escogida". Passeggi y Souza (2008) definen el memorial académico como:

"género académico autobiográfico, por medio del cual el autor se (auto)evalúa y teje reflexiones críticas sobre su recorrido intelectual y profesional, en función de una demanda institucional. El interés de su narrativa es clarificar experiencias significativas para su formación y situar sus proyectos actuales y futuros en el proceso de inserción académica y ascensión profesional" (Passeggi y Souza, 2008, p. 120).

Tal narrativa se suma a un conjunto de documentos que son presentados para la inscripción del candidato al concurso público de pruebas y títulos. El concurso público se refiere a una plaza de Profesor Libre-Docente o Titular ofrecida por un departamento y que será cubierta mediante la selección de uno de sus profesores interesados en el ascenso profesional. El ritual es encabezado por una comisión indicada por la institución, compuesta por cinco profesores que ya poseen el título ofrecido por la convocatoria, siendo solamente uno del departamento y los demás de otras instituciones de enseñanza superior. Durante dos o tres días la comisión certifica el desempeño académico del candidato a través de la puntuación obtenida por la documentación presentada por el docente de sus diferentes realizaciones profesionales, y realiza la evaluación de mérito del memorial (o de la tesis) con su respectiva presentación y defensa. En algunos casos, el ascenso profesional marca más el reconocimiento de un nuevo nivel funcional, que se fue consolidando a lo largo de los años en etapas sucesivas, y un aumento económico y financiero en el salario, que un nuevo nivel de producción académica del candidato.

El documento posee una clara dimensión autobiográfica al exponer una trayectoria profesional y personal, alterando su naturaleza por la incorporación de dimensiones subjetivas a lo largo del tiempo. Actualmente, como escritura de sí, el memorial académico está condicionado por una tradición institucional y regulado por normas expresas en la convocatoria de concurso público, lo que implica que puede poseer diferentes niveles de subjetivación.

En las dos últimas décadas la narrativa de los aspectos objetivos de las trayectorias de los profesores en términos profesionales y organizacionales se mezcla con los aspectos personales y subjetivos en el documento, permitiendo a sus autores establecer una relación entre su identidad personal y social, o sea, entre su individualidad y su rol profesional, para poder situarse frente a su contexto personal y socio-histórico.

Una cuestión relevante es que, en el caso de los profesores universitarios, como intelectuales, el determinante del "nombre" ocupa una centralidad que condiciona la descripción del recorrido entre diversos campos, sistemas y configuraciones sociales en las cuales un discurso profesional y académico garantiza mantener bajo control, o alejadas, las dimensiones sensibles y afectivas. Como apunta Bourdieu (1996, p. 78), el registro civil agrega "una identidad social constituyente y perdurable que garantiza la identidad del individuo biológico en todos los campos posibles en los cuales él interviene como agente, esto es, en todas sus historias de vida posibles." Por su parte, Lejeune (2008) relaciona tal dimensión con el texto autobiográfico:

"Es, por tanto, en relación al nombre propio que deben ser situados los problemas de autobiografía. (...) Es en ese nombre que se resume toda la existencia de lo que llamamos de autor: única marca en el texto de una realidad extratextual indudable, remitiendo a una persona real, que solicita, de esa forma, que le sea en última instancia, atribuida la responsabilidad de la enunciación de todo el texto escrito" (Lejeune, 2008, p.23).

Para el ciudadano el nombre suele constituir la expresión de su identidad. En el caso del intelectual, el nombre expresa no solo esa identidad personal, sino que se proyecta como 
guardián de una obra propia. Esta obra, que está construida social e históricamente, se muestra como un reflejo de realizaciones, vínculos, simpatías, antipatías, apreciaciones e indiferencias en un espacio relacional concreto y delimitado.

Teóricamente, el memorial debe reflejar no solo los aspectos subjetivos del narradoracadémico, sino también los contextos intelectuales en los cuales se inserta. En este sentido, la crisis paradigmática sufrida por las ciencias humanas y sociales en las últimas décadas, que se expresa, entre otros aspectos, por el giro lingüístico y por el retorno de la narrativa, se expresa en la orientación discursiva de esos documentos.

La perspectiva autorreflexiva en los memoriales se amplió a lo largo de las últimas décadas y estableció de forma creciente un enfoque más subjetivo, en el que se valoran más las experiencias recordadas, la exposición de vivencias individuales y la fusión de recuerdo y evaluación. Además, es habitual explicitar "eventos destacados", "episodios centrales", "memorias definidoras del self" y "memorias vividas", expuestos como referencias de identidad personal y profesional, y también de percepción de una trayectoria al mismo tiempo colectiva y singular.

El memorial, pues, se presenta como documento escrito de naturaleza académica, legitimado como espacio para el tratamiento de las vivencias del narrador en una multiplicidad de aspectos, desde los profesionales, como docente, investigador, gestor y agente de extensión, hasta los personales, como las relaciones cotidianas. No obstante, muchos profesores universitarios, vinculados a los referentes académicos clásicos, en los cuales se busca una objetividad analítica, no se sienten cómodos a la hora de abordar en sus narrativas dimensiones subjetivas y experienciales.

Algunos, por tanto, optan por una estructura narrativa que se traduce en un ejercicio de enumeración, en donde la carrera no se mezcla con la vida. Así, se enfatiza el itinerario profesional, dotada de una lógica interna, que se presenta de forma coherente, como narrativa lineal, unidimensional y objetivada, que ordena un conjunto de éxitos profesionales sucesivos y acumulativos, con el formato de una lista exhaustiva de un conjunto de elementos mensurables y ordenados, que reflejan y objetivan los méritos del autor.

En realidad, tal enumeración resulta en la afirmación de una lógica de enunciación externa. El discurso producido no es del autor, sino de "otros", particularmente de las instituciones que legitiman su evolución profesional y académica. Es como si el autor dijera que no habla de sí mismo, sino que sus títulos hablan por él. Lo que llama la atención es que profesionales de distintas áreas y de distintas generaciones se aproximan con mayor dificultad a modelos enumerativos, entendidos como más cartesianos, o a modelos narrativos, más hermenéuticos, pero ambas posibilidades son representaciones de sí y del mundo, configurando estrategias específicas de autorrepresentación y autofiguración. Tal elección, entre producir un memorial como currículo o un memorial como memoria, refleja en gran parte las "reglas del juego" de cada campo académico y el ethos de cada generación y se traduce en concepciones de la separación entre sujeto y objeto, y entre subjetividad y conocimiento.

Las elecciones entre enumeración y narración reflejarían las determinaciones del campo de cada área o disciplina, mostrando de forma más o menos directa el contraste entre las formas de escritura tradicionales del profesor entre sus diferentes quehaceres académicointelectuales y su memorial. Esa tensión, según Waizbort (1998, p. 77-78), sería el resultado de las condiciones constitutivas del conocimiento cartesiano en la búsqueda de la diferenciación del saber científico (en el cual prevalece la regla de la doctrina primus, stilus ultimus), en relación a la narrativa literaria (moldeada por la regla stilus primus, doctrina ultimus), y que en las ciencias sociales es reivindicada por la distinción entre "tratado" y "ensayo". Las inquietudes sobre las fronteras entre saber científico y narrativa literaria han sido punto de inflexión en diversos autores de diferentes áreas, como en que ofrecen ideas 
prometedoras sobre el desempeño del investigador como performance en el interior de la ciencia (Daston y Sibum (2003), que problematizan de manera bastante original las determinaciones del campo histórico sobre el desarrollo de habilidades y perspectivas intelectuales de los historiadores (Paul, 2014), que buscan caracterizar modelos de escritura autobiográfica entre historiadores (Aurell, 2008). En el ámbito específico de la Antropología, se ha consolidado el concepto de "autoetnografía", mediante la explicitación de la dimensión autobiográfica en la actividad etnográfica (James, y James, 1986; Fischer y Marcus, 2003).

La estructura del memorial debe, obligatoriamente, atender a ciertas dimensiones formales específicas, determinadas en líneas generales por las propias convocatorias de los concursos públicos de libre docencia y de titularidad: el candidato debe presentar su formación académica; los vínculos laborales que desarrolló; las actividades de enseñanza y las orientaciones de posgrado; una breve descripción de su línea de trabajo y de las relaciones de colaboración científica que consiguió establecer; los principales logros en los ámbitos de la enseñanza, la investigación, la extensión y la gestión en la institución; los resultados obtenidos en investigaciones; las citas recibidas de artículos en revistas arbitradas de ámbito nacional e internacional; las estancias de investigación y las visitas científicas; las presentaciones en congresos; las ayudas y becas conseguidas; y la participación en tribunales de defensa y otras actividades. En este aspecto es posible discutir si las determinaciones formales de las narrativas institucionales, como las de naturaleza judicial, administrativa o económica, pueden favorecer una percepción distorsionada de la persona, al condicionar los modelos y los enfoques narrativos.

Câmara y Passeggi (2012) identifican, a partir del análisis de algo más de 300 memoriales académicos presentados en concursos públicos de la Universidad de São Paulo y de la Universidad Federal de Bahía, tres estructuras narrativas, vinculadas a tres etapas históricas sucesivas: fase de institucionalización, entre 1930 y 1950; fase de consolidación, entre 1950 y 1970; y fase de diversificación, a partir de 1980. La evolución ha implicado el abandono de ciertas características formales, mientras coexistían tradiciones que han sido mantenidas e innovaciones introducidas. En los últimos años, como indican Câmara y Passeggi (2012), coexisten memoriales que siguen el modelo enumerativo, otros que optan por modelos narrativos y algunos que usan estructuras híbridas.

La primera fase, de institucionalización, fue dotada de tal rigidez formal que la desobediencia de la secuencia de los ítems exigidos en las convocatorias podría justificar el rechazo del candidato, aunque igualmente se producían eventuales referencias personales como descripciones del ambiente familiar y escolar, por ejemplo.

La segunda fase, entre las décadas de los 50 y los 70, aproxima enormemente el memorial al curriculum vitae, con un uso generalizado del modelo enumerativo de los eventos de la vida científica de los profesores y sus realizaciones. Esta objetivación puede ser explicada a partir de dos factores: a) el contexto político y social representado por la represión del régimen militar que transformaba la documentación en un mecanismo de supresión del sujeto de las estructuras sociales de las cuales forma parte, al hacer que las referencias a los individuos en los registros se realicen mediante números; b) la forma como la universidad brasileña sufre un proceso de restructuración con amplia influencia de los modelos académicos norteamericanos, en los que la objetividad del curriculum vitae, tan del gusto de la tecnocracia estatal, era el patrón formal más deseable, debido a su instrumentalidad cuantitativa.

Finalmente, la última fase, a partir de la década de los 80 , permite una creciente diversificación que se extiende hasta el momento actual, marcado por la relevancia de la perspectiva personal, como consecuencia del giro lingüístico y subjetivo.

Es incuestionable que la aproximación a esta dimensión narrativa presenta una valiosa ganancia cualitativa. Además, permite la incorporación de dimensiones que están más allá de 
la enumeración, permitiendo la percepción de la carrera como algo que engloba palabra, imagen, gesto y forma de vida. Esto hace posible transformar cada experiencia vivida en expresión de una performance que, sumada a otras, forma una imagen construida a partir de los proyectos, las posibilidades y los deseos del docente. Así, la relativa familiaridad del profesor universitario con el lenguaje escrito, junto al esfuerzo autorreflexivo, posibilitarían superar las limitaciones criticadas por Nora (1989, p. 11), bajo las sugerentes etiquetas de "autobiografía falsamente literaria", "confesiones inútilmente íntimas", "profesión de fe abstracta" o "intento de psicoanálisis salvaje".

\section{Rasgos sociales, epistemológicos y narrativos de los memoriales académicos}

"La primera cosa a observar es que no solo el futuro - "la ola del futuro" -, sino también el pasado, es visto como una fuerza, y no, como en prácticamente todas nuestras metáforas, como un fardo con el que el hombre tiene que cargar y de cuyo peso muerto los vivos pueden o deben deshacerse en su marcha para el futuro." (Hannah Arendt, Entre el pasado y el futuro.)

El memorial académico presenta una dimensión subjetiva, al incorporar una dimensión narrativa en la que el sujeto tiene una posición central. Esto implica transcender el lenguaje de los documentos burocráticos y de sus discursos formales, que de manera aséptica, científicamente ponderada y técnicamente equilibrada caracterizan las escrituras de tipo administrativo.

$\mathrm{Al}$ interior del relato formal de logros profesionales se hacen visibles, por presencia o ausencia, dimensiones diversas en el conjunto caótico de eventos y sentidos atribuidos que forman la existencia de los académicos y de los no académicos, obteniéndose elementos no solo para una historia de vida, sino para una historia profesional e institucional, que están amenazadas de perderse en los archivos burocráticos de la universidad.

Las reflexiones sobre la propia trayectoria, la construcción de la identidad profesional y los vínculos desarrollados entre formación y práctica docente, todo ello ofrece un rico panorama del universo subjetivo de los procesos de enseñanza-aprendizaje, a partir de la percepción del profesor. Entre las temáticas que suelen aparecer en los memoriales, y que configuran estilos narrativos específicos, podemos apuntar la exploración de los orígenes, la búsqueda de metas y valores, la dimensión organizacional, el énfasis en permanencias o cambios, el juego de fuerzas en las que se inserta la vida profesional y personal, la autorreflexión y la continuidad del yo.

La concepción romántica del trabajo intelectual ha privilegiado la figura del "genio", que solitariamente realizaba sus contribuciones en un campo específico del conocimiento. Frente a esta visión tradicional, los memoriales favorecen una visión basada en la construcción social del conocimiento, lo que permite percibir las referencias teóricas e intelectuales y las concepciones del mundo compartidas en un ámbito dado de investigación, a la vez que las dimensiones subjetivas de una actividad que, en numerosas ocasiones, tanto en la enseñanza como en la investigación, sitúa al individuo frente a sí mismo y a los demás. Por otra parte, no deberíamos de olvidar que la narrativa biográfica surge como una rica evaluación cualitativa, en contraste con las dimensiones cuantitativas y productivistas, que actualmente son hegemónicas en el mundo académico.

Hay que resaltar que el memorial es un producto histórico e institucional, heredero de una determinada concepción del conocimiento y de la carrera académica, marcada por la dimensión acumulativa y racionalista. Y que actualmente, en medio del giro lingüístico y subjetivo, este memorial tributario de la concepción tradicional, concebido como curriculum, convive con una nueva versión del memorial como narrativa, ubicado dentro de las concepciones de "escritura de del yo", del "egodocumento", de la "autoetnografía" y de la 
"ego-historia". Además, existen modelos híbridos de diferentes tipos, que implican compromisos variados con los dos modelos mencionados.

El contraste necesario en los memoriales entre la estructura enumerativa (cartesiana) y la autorreflexiva (hermenéutica), y la constatación de la existencia de modelos híbridos, no alteran el hecho de que son el resultado de una más de las actividades solitarias a las cuales el profesor universitario se dedica. Por otro lado, existe una dimensión relacional, pues los memoriales son reevaluados, reestructurados y compartidos en un proceso de resignificación social, en relación con el tribunal evaluador y con los posibles lectores.

En ese sentido, además de los diferentes referentes que comúnmente se encuentran en este tipo de narrativa (el orden cronológico, la contextualización del periodo histórico, la referencia a los orígenes familiares como el "punto de partida", las evaluaciones críticas sobre la actividad intelectual y las transiciones relevantes), nos llama poderosamente la atención la cuestión de los silencios que también se hacen presentes y que nos dicen algo desde el vacío que significan.

En el proceso de resignificación de la trayectoria individual que es rememorada, organizada, ordenada y sintetizada como experiencia y sensibilidad, el autor del memorial organiza su escritura en relación a un lector imaginario, compuesto por una proyección hipotética de cómo podría ser el tribunal de defensa del concurso público al cual se someterá, y por las características exigidas por la convocatoria del concurso.

En la inmensa mayoría de las instituciones existe una tensión evidente, derivada del difícil convivir de egos y vanidades entre colegas, así como de la necesidad de gestionar complejas dimensiones personales, intelectuales e ideológicas, por las cuales se producen aproximaciones y alejamientos entre individuos y grupos en la universidad. Esto puede provocar que los autores de los memoriales eviten exponer opiniones negativas sobre los colegas o la institución, que podrían originar enfrentamientos o conflictos.

Como documento público, el memorial está destinado formalmente al tribunal, pero la institución suele ponerlo a disposición de colegas y potenciales interesados para su consulta y lectura. No podemos olvidar que los colegas son profesionales que comparten con los autores de los memoriales ocupaciones similares, referentes teóricos (convergentes o divergentes), redes de relaciones, sentimientos de pertenencia o exclusión e identidades diversas. Por ello, explicitar divergencias es como mínimo colocarse en una posición de desgaste y podría despertar antipatías innecesarias.

Otra particularidad, indiferente al estilo narrativo, hace que el relato desarrolle una perspectiva sedimentaria y enfatice los logros, eliminando o minusvalorando los fracasos, de modo tal que la carrera en la mayoría de las ocasiones es descrita de forma objetivada y como una consecuencia de sucesivos éxitos que se sobreponen. Cuando se presentan derrotas y fracasos, suele ser para justificar posteriores actos de superación.

También llama la atención la escasa presencia de la percepción de la dimensión performativa sobre el oficio, el métier, en el sentido de que el proceso de interacción con los estudiantes y pares es totalmente naturalizado, descarnado de las exigencias de empatía, comunicabilidad y expresión que median la relación pensar-hacer, y hasta cuando hacen referencia a la influencia sobre los propios trabajos de autores como Richard Schechner, Victor Turner, Franz Boas, Clifford Geertz o Michael Taussig, la auto-percepción de su actuación performativa se hace poco presente.

En una referencia recurrente, que es la descripción de los orígenes y de episodios destacados de la trayectoria, en general, las cuestiones de clase se hacen mucho más presentes que las de género y raza, no solo en relación a sí mismo, sino también en relación al otro. Diversos aspectos contribuyen a ello, particularmente la cuestión generacional (la Libre docencia es alcanzada, en general, por profesionales con más de 40 años, y la Titularidad por mayores de 50 años), que influye en muchas de sus referencias de formación, en las que se 
inserta una percepción más acentuada de los conflictos de clase, una naturalización del reducido número de negros en las aulas universitarias del país, una supervivencia de una tradición misógina en el campo intelectual que busca identificar como fragilidad, limitación e incapacidad aspectos de la condición femenina, la homofobia y el estigma de la condición homosexual, entre otras.

Se suma a esas ausencias de percepción una determinada desconsideración por la dimensión física y corporal de la existencia. En efecto, esta dimensión solo aparece en tres de los 39 memoriales analizados. Parece como si el intelectual fuese unidimensional o estuviese totalmente alejado de ganar peso, del debilitamiento de la vista, de los pequeños desgastes o de las lesiones por esfuerzo repetitivo de escribir, leer, hablar o hasta de las dolencias y problemas habituales del curso de la vida (problemas o angustias con la presión arterial, diabetes, colesterol, cardiopatías, problemas respiratorios).

Los problemas físicos o psíquicos, que eventualmente son vividos por todos, no existen en los memoriales, aunque hayan afectado la actividad docente o la producción académica del narrador, como si así fuese afirmada la dualidad del cuerpo y del alama, o de la mente y el físico. En una sociedad en la que el fetiche del cuerpo y el cuidado de la salud son tan recurrentes, esas referencias prácticamente son inexistentes en las narrativas.

Pero más allá de sus silencios, los grandes méritos de tales textos son que, además de su obvio valor histórico, como relato de una experiencia docente y de las vivencias e identidades que en ella se relacionan dentro de un determinado contexto socio-cultural, afirman su valor didáctico, al colocar el yo del autor y sus experiencias en el pasado, en el presente y en el futuro, en referencia a otro autor, o lector, y por la posibilidad de compartir significados.

En una sociedad en donde se amplían de forma progresiva tensiones, antagonismos, fanatismos y fundamentalismos, la construcción de identidades y alteridades de forma relacional y dialógica se muestra como una necesidad urgente. En este sentido, los memoriales académicos nos parecen un ejercicio intelectual que pone de relieve las tensiones, mediaciones, complejidades y posibilidades de los enfoques narrativos, cuyo análisis puede ser útil para repensar el lugar de la experiencia, de la subjetividad y de la historia en nuestros contextos universitarios actuales.

\section{Referencias bibliográficas}

Arfuch, L. (2002). El espacio biográfico: dilemas de la subjetividad contemporánea. Buenos Aires: Fondo de Cultura Económica.

Arfuch, L. (2013). Memoria y autobiografía. Buenos Aires: Fondo de Cultura Económica.

Aurell, J. (2008). Del logocentrismo a la textualidad: la autobiografía académica como intervención historiográfica. Edad Media. Revista de Historia, 9, 193-222.

Bourdieu, P. (1996). A ilusão biográfica. En Ferreira, M. M.; Amado, J. (Eds.) Usos e abusos da história oral). Rio de Janeiro: FGV, 181-191.

Câmara, S. C. X. y Passeggi, M. C. (2012). O gênero memorial acadêmico no Brasil: concepções e mudanças de uma autobiografia intelectual. En Jornada Nacional do Grupo de Estudos Línguísticos do Nordeste, XXIV, Natal: UFRN, 4 a 7 de set. Anais [Consultado el 7 de enero de 2016], http://www.gelne.org.br/Site/arquivostrab/1517-ARTIGO-GELNE-2012SandraCXCamara-Passeggi.pdf . 
D’Onofrio, S. (1999). Metodologia do trabalho intelectual. São Paulo: Atlas.

Daston, L. y Sibum, H. O. (2003). Introduction: Scientific Personae and Their Histories. Science in Context (Tel Aviv), 16 (1), 1-8.

Delory-Momberger, C. (2001). Le sens de l'histoire : moments d'une biographie. Paris: Anthropos.

Delory-Momberger, C. (2004). De l'invention de soi au projet de formation. Paris: Anthropos.

Fischer, M. M. J. y Marcus, G. M. (1986) Anthropology as cultural critique. Chicago: University of Chicago.

Foucault, M. (1990). Tecnologías del yo y otros textos afines. Barcelona: Paidós.

Gauer, G., Gomes, W. B. (2008). Recordação de eventos pessoais: memória autobiográfica, consciência e julgamento. Psicologia: Teoria e Pesquisa (São Paulo), 24 (4), 507514.

González-Monteagudo, J. (2008). Des approches européennes non francophones en histoires de vie (Note de synthèse). Pratiques de Formation/Analyses. Revue internationale (University of Paris VIII, France), 55, 9-83.

James. C.; James, M. (1986). Writing Culture. The poetics and politics of ethnography. Los Angeles: University of California Press.

Lejeune, P. (2008). O pacto autobiográfico: de Rousseau à internet. Belo Horizonte: UFMG.

Moraes, I. N. (1985). Elaboração da pesquisa científica. São Paulo: Álamo / Faculdade IberoAmericana.

Nora, P. (1989). Ensaios de Ego-história. Lisboa: Edições 70.

Passeggi, M. C. y Souza, E. C. (Eds.). (2008) (Auto)biografia: formação, territórios e saberes. Natal: EDUFRN / São Paulo: Paulus.

Passeggi, M. C.; Souza, E. C. y Vicentini, P. P. (2011). Entre a vida e a formação: pesquisa (auto)biográfica, docência e profissionalização. Educação em Revista (Belo Horizonte, Brasil), 27(01), 369-386.

Paul, H. (2014). What is a Scholarly Persona? Ten theses on virtues, skills, and desires. History \& Theory (Middletown), 53(3), 348-371.

Sarlo, B. (2007). Tempo passado: cultura da memória e guinada subjetiva. São Paulo: Companhia das Letras.

Schweiger, K. (2009). Zur brasilianischen Textart "Memorial Acadêmico": wie man sich in Brasilien auf eine akademische Stelle bewirbt. Pandaemonium germanicum (São Paulo, Brasil), 14, 84-104.

Silva, W. C. L. (2015a). Para além da ego-história: memoriais acadêmicos como fontes de pesquisa autobiográfica. Patrimonio e Memoria (Assis, São Paulo), 11(1), 71-95. 
Silva, W. C. L. (2015b). A vida, a obra, o que falta, o que sobra: memorial acadêmico, direitos e obrigações da escrita. Revista Tempo e Argumento (Florianópolis, Brasil), 7(15), 103-136.

Waizbort, L. (2011). Glosa sobre a universidade, a formação e as disciplinas do saber, por ocasião de um concurso universitário. ARS (São Paulo), 9(17), 138-145. 